\title{
Fragile familiarity in transnational home care arrangements for older people
}

\author{
By Karin van Holten ${ }^{1}$, Heidi Kaspar ${ }^{1}$ \& EVA SOOM-Ammann ${ }^{2}$
}

\begin{abstract}
This paper examines the notion of familiarity in live-in elder care settings and how it is challenged, changed, and reestablished. Live-in care is a strategy to prevent disruptions and preserve familiarity in enabling older persons in need of extensive care to stay at home - and thus, to enable ageing in place. This paper problematizes this strategy based on interviews with family caregivers who engaged a migrant live-in care worker in Switzerland. The key argument is that live-in care arrangements constitute an all-embracing form of inserting formal, paid-for care service delivery into the informal, private, intimate space of home. The live-in care arrangement not only challenges the familiarity of the home space, but also seems to ask for strategies of adaptation to familiarize the unfamiliar. Therefore, the introduction of live-in care is consequential for all involved parties and requires largely underestimated efforts to adapt to the new home space.
\end{abstract}

Keywords: care migration, familiarity, home, home care, live-in care, long-term care, old-age care, transnational care.

${ }^{1}$ Karin van Holten $\mathcal{E}$ Heidi Kaspar, Department of Health Sciences, Careum School of Health, Kalaidos University of Applied Sciences, Zurich, Switzerland

${ }^{2}$ Eva Soom-Ammann, Department of Health Professions, Bern University of Applied Sciences, Bern, Switzerland 
International Journal of Ageing and Later Life

\section{Introduction}

Ageing is about change and adaptation. While ageing, bodies, and capacities are subject to change, physical and cognitive limitations emerge and create new care needs and requirements that foster well-being. Ageing prompts reconsidering, negotiating, and altering established daily routines and preferences. This may lead to material transformations of the home, such as added handles in the shower, removed carpets on the floor or installed high-tech devices such as sensor-integrated floors with automated alarm systems (Doh et al. 2016).

Caring for the older people is about adaptation, too. Social ties and networks are likely to alter with increasing dependency on support (Allan \& Crow 2001; Chambers et al. 2009; Silverstein \& Giarrusso 2010). Not only are changing age-related needs and dependencies affecting preexistent social relations, but they also introduce new actors to social networks and to the home: unfamiliar persons providing health and/or social care may enter the domestic space and, hence, challenge the specific quality of home considered as a place of privacy and intimacy (see, e.g. Angus et al. 2005; Dyck et al. 2005; Haak et al. 2007).

In a setting of ambulant caregiving, the potential challenge to privacy, intimacy, and familiarity of the home space is an episode of exception. Here, professional healthcare providers enter the home space on a timely restricted basis. But when live-in caregivers move in to provide aroundthe-clock home care, the exception stretches in time and pervades the everyday, posing a fundamental challenge to the home space. This starkly contrasts with the intentions of opting for live-in care arrangements, namely, to prevent disruptions and promote continuity (van Holten et al. 2013). Family caregivers who arranged live-in care equate preserving familiarity with remaining at home (ibid.). Such an equation presumes the home space as an immutable entity that once it has been made familiar remains familiar.

In this paper, we examine the notion of familiarity in live-in care settings for older people and how it is challenged, changed, and reestablished in the course of altering home care settings. In doing so, the paper contributes to the body of work that reflects on care in the home space. Research in this field focuses on consequences of professional health and social care in the home (e.g. Angus et al. 2005; Dyck et al. 2005; 
Steptoe et al. 2015), or on different kinds of care, that is, formal and informal care, including reflections on the specific role of family caregivers (e.g. Milligan 2000, 2005; Milligan \& Wiles 2010; Twigg 2001). From both perspectives, the literature illustrates that the home care setting is characterized by blurring boundaries between formal and informal, paid and unpaid care on the one side and between health and social care on the other side. Live-in care in Switzerland (as in other countries, for example, Germany, Austria, and Italy) is provided by a paid-for care worker who usually migrates from abroad for this job, stays in the home for some weeks or months, taking turns with colleagues (i.e. circular migration patterns). Live-in care arrangements are also referred to as around-the-clock care or 24-hour care, indicating that comprehensive care needs are met in private households by a migrant care worker at place. Furthermore, this term already implies problematic dimensions inherent in live-in care arrangements, such as the dissolution of boundaries between work and leisure time and the tendency toward exploitative living and working conditions of migrant care workers. To sum up, one could say, this home care arrangement is a strategy to enable ageing in place that, while being contested, is gaining popularity (for an overview, see Anderson 2012; Lutz 2011; MetzGöckel et al. 2008).

Based on a secondary analysis of interviews with family caregivers in Switzerland who had arranged a migrant live-in care worker, we problematize the live-in care arrangement. We show how discursive negotiations of such arrangements by family caregivers illustrate the fragility of familiarity and the contestation of home as a familiar place in these settings. The key argument is that the live-in care arrangement constitutes an extreme form of inserting paid-for care service delivery into the private, intimate space of home. The introduction of migrant live-in caregivers into home care settings not only challenges the familiarity of the home space, but also seems to ask for strategies of adaptation to familiarize the unfamiliar, thus to redefine the meaning of home or to reestablish home by integrating up to now unfamiliar elements or persons into the home space. Therefore, the introduction of live-in care is consequential for all involved parties and requires largely underestimated efforts to adapt to the new circumstances. 
International Journal of Ageing and Later Life

The paper starts by situating live-in care within the Swiss context of long-term home care. It moves on by reflecting on the concept of familiarity in the framework of home and home care. These reflections inform the presentation of our empirical insights, drawn from a secondary analysis of in-depth interviews with family caregivers. We conclude this article by summarizing how familiarity in the home gets challenged through live-in care arrangements and what this means for the involved persons.

\section{Live-in Care - Transnationally Organized Long-Term Care at Home}

As in most European societies, the Swiss long-term elder care system is challenged by demographic developments, cost calculations, and increasingly diversified lifestyles aiming at a maximum of autonomy also when care needs arise. Across Europe, current government policies focus on supporting older people to remain at home as long as possible (Bettio \& Verashchagina 2010; Genet et al. 2012). In 2016, 283,528 people of all ages received professional home care in Switzerland; this is an $11 \%$ increase in comparison to 2015 and even one of 38\% compared to 2011 (Federal Statistical Office 2017). Even though there are still regional differences within Switzerland, available data clearly show a continuous shift into the outpatient sector for already more than a decade (Füglister-Dousse et al. 2015; Werner et al. 2016). Domestic care services are expanded, but in many countries there is still a vast gap between the care needs and the availability of comprehensive care services at home (Colombo et al. 2011). To enable long-term care in private households, both healthcare and social care are essential (Colombo et al. 2011: 46). The latter consists of supportive care tasks such as housekeeping, cooking, social support, and so on. These tasks are of particular relevance for people's ability to stay at home as long as possible, which is both a healthcare policy goal and an individual preference (Otto et al. 2014, 2015). We refer to this broad definition of different forms of health and social care when we talk about long-term care needs in Swiss households.

However, in terms of funding and reimbursing services, the Swiss healthcare system clearly distinguishes between health and social care, whereby a narrow understanding of health, in tendency excluding 
nonsomatic aspects, applies. Supporting and supervising a person with dementia, for example, does not count as healthcare. As a consequence, only somatic ${ }^{1}$ healthcare services are reimbursed by health insurances, and a family doctor's prescription is required to do so. Social care services, on the contrary, have to be financed out-of-pocket by the persons in need of care (Federal Statistical Office 2015: 2). In consequence, the Swiss long-term home care system heavily relies on families both in terms of funding and personal engagement. Private expenditure for long-term care in Switzerland sums up to a final estimate of about $36 \%$ of all costs, which is more than double to the European average (Colombo et al. 2011: 46-47; OECD 2011: 46-47). As a result, the provision of social care and support in household chores are the primary challenges for long-term care provision.

Filling the gaps of unmet care needs, new markets are developing. One of these markets is the mediation of migrant home care workers from economically less privileged regions to work and live in households of people with long-term care needs (Schwiter et al. 2015). Reliable data on the number of live-in migrant care workers are scarce because many migrants do not register in the host countries (Rodrigues et al. 2013), and even if they do, official immigration data often are not sufficiently differentiated in terms of working sectors (Frey et al. 2016). What is known from the literature is that the phenomenon of migrant care workers is closely linked to long-term care and immigration policies of the host countries (Lamura 2013; Rostgaard et al. 2011; Shutes \& Chiatti 2012), and to the kind of care regime (van Hooren 2012). For Switzerland, the estimated share of domestic care workers coming from abroad lies between 5000 and 30,000 (Frey et al. 2016). In comparison to Germany, where the number of migrant care workers employed by private households is estimated between 50,000 and 200,000 (Di Santo \& Ceruzzi 2010), the Swiss share appears to be rather low. This may be due to the fact that in the Swiss healthcare system there is only very limited cash for care transfer. Hence, if people engage someone for long-term home care, they have to

\footnotetext{
${ }^{1}$ Measures to monitor and support mentally ill persons in basic everyday coping, such as development and practice of an adapted daily structure or target-oriented training to design and promote social contacts may be reimbursed by health insurances, but only if based on a diagnose of mental illness, which is not the case for dementia.
} 
International Journal of Ageing and Later Life

pay out-of-pocket. Consequently, those who cannot afford this remain dependent on family caregivers or institutional care (van Holten et al. 2013). Nevertheless, live-in care arrangements with migrant care workers are also becoming more and more prevalent in Switzerland (Frey et al. 2016). Domestic migrant care workers mainly come from central and (middle-)Eastern European countries and are mostly women (e.g. Frey et al. 2016; Lutz 2011; Schilliger 2014), well educated (although in most cases not trained in nursing or healthcare), and travel back and forth between the host and the home country (Frey et al. 2016; Rodrigues et al. 2013; Schilliger 2014; van Holten et al. 2013).

The practice of hiring a migrant care worker to live and work in private households, be it for domestic work, child care, and/or care for older people (and sometimes all in one, see Huang et al. 2012), is part of what is referred to as transnationalization of care. We use this term to refer to the recurrent cross-border mobility of care workers and the search activities of those in need of care services. Research on the transnationalization of care "combines structural understandings of global power relations with an emphasis on social interactions between defined actors" (Yeates 2011: 1109). Following this focus on the intertwining of the micro-, meso-, and macro-level, scholars have examined immigration policies and the implementations thereof, concluding that engaging a migrant live-in care worker is not just an individual practice, but also a national strategy, consisting of discourses, policies, and practices that allow and even foster the delegation of care down the economic gradient (e.g. England \& Dyck 2012; Shutes \& Chiatti 2012; Williams 2012). According to Yeates (2011: 1113), care transnationalization can be viewed as "processes of heightened connectivity evolving around consciousness, identities, ideas, relations and practices of care which link people, institutions and places across state borders." Hence, care arrangements including a live-in migrant care worker are transnational in the sense that people facing shortcomings of local and national long-term care provision start searching and organizing local long-term care across national borders. Nare (2012: 184) calls this model of families buying in care labour provided by a migrant worker the "transnational market familism" She argues that these dynamics are part of a political economy of care where welfare provision is organized in a transnational context. On a translocal level, these transnationally organized care arrangements involve repeated movements of people between 
two (or more) countries and create spaces that span beyond the individual and integrate parts of, respectively, local networks into an emerging new - transnational - network. Furthermore, employing a migrant care worker, rather than providing care within the family, implies a number of transformations, foremost with respect to the home of the elderly person. For example, it hosts new household members, who simultaneously are members of another, distant household and family. As such, the home employing a migrant live-in care worker together with the distant other household of the care worker builds a transnational space of domestic care which transforms the care relationship between the caregiver and the care receiver into a complex relationship between the family caregiver organizing care, the migrant care worker and the person in need of care (see, e.g. Nare 2012). Home care usually establishes translocally dispersed care relations and responsibilities involving the persons cared for at home, family caregivers' homes, ambulant paid caregivers' offices, general practitioners' offices, and people moving between these places. A live-in care arrangement involving migrant caregivers expands these relations, responsibilities, and circulations to distant places across national borders.

For Switzerland, this kind of "transnationalisation of care" is accompanied by an increasing number of scientific studies focusing on diverse dimensions of this phenomenon in the Swiss context. They examine issues such as the experiences of live-in migrant home care workers (Schilliger 2014; Truong 2011), the intermediary practices of agencies (Schwiter et al. 2015; Truong et al. 2012), or the diverse judicial aspects relating to Swiss labor and migration legislation (Medici 2011, 2016). Others investigate the gaps in long-term care provision in terms of funding and services and the corresponding needs of private households engaging live-in migrant home care workers (van Holten et al. 2013), or the experiences of professional home care providers when getting in contact with migrant care workers (Jähnke \& van Holten 2013, 2015).

All these papers link the phenomenon of live-in care arrangements in the Swiss context to problematic dimensions of global inequality, to the care chain phenomenon, and to the specific vulnerability of the migrant domestic care workers as well as to marketization and individualization of care. Hence, they frame their work within the overall scientific debate of care transnationalization as illustrated above. 
International Journal of Ageing and Later Life

However, little is known about family caregivers' motives, understandings, and experiences with regard to live-in care arrangements (exceptions to this are Chiatti et al. 2013; Petry et al. 2016). This is an important research gap because family caregivers in Switzerland, as well as worldwide, are the backbone of long-term home care. Their contributions - if estimated in monetary terms - clearly exceed annual healthcare costs in the formal sector (Colombo et al. 2011; De Pietro et al. 2015; Rudin \& Strub 2014). Family caregivers play a crucial role in providing, organizing, and managing care (Bischofberger 2011; Levine et al. 2010, 2013). As they bear the main caring responsibility, it is usually family caregivers who consider, propose, push, and arrange live-in care arrangements and actually employ live-in care workers (van Holten et al. 2013). Therefore, their perspective is pivotal if we want to know more about why and how live-in care arrangements are formed and how they affect the persons involved (see van Holten et al. 2013).

\section{Method and Data Corpus}

This paper is based on interviews conducted by the first author for a study mandated by the Swiss Health Observatory (OBSAN). The study "Care Migration - Transnational Care Arrangements in Private Households" was the first in the Swiss context to take into account the perspective of family caregivers on transnational live-in care settings (van Holten et al. 2013). The project was reviewed by the Institution Review Board (IRB) of the Kalaidos University of Applied Sciences which provided the project with a letter of good standing. Between March and November 2012, eleven interviews were conducted with family caregivers. The interviews were in-depth with a narrative character, lasting 1-2 hours. All the interviews have been transcribed verbatim.

Within the framework of the mandate at that time, all interviews were analyzed by means of structured content analysis (Mayring 2007). The focus of the analysis was laid on family caregivers' reasons and motives for engaging migrant domestic care workers. Main results presented in the study report (van Holten et al. 2013) were the following: family caregivers decide to engage migrant domestic care workers because they strive for stable, comprehensive home care arrangements which - so the shared overall argument - the healthcare system is not able to provide, 
neither in terms of material services nor in terms of the desired quality (personal, attentive, individual, flexible, and comprehensive) - at least not within the available cost limits of the interviewed persons (ibid.). Hence, the interviews showed that live-in care arrangements with migrant care workers fill in existing gaps of the Swiss long-term home care system.

Due to the narrative character, the interviews provided much more information than was extracted through content analysis. Particularly, the interviews contained sequences concerning difficulties related to (daily) routines, intimacy, autonomy, conflicting social dynamics, and strategies - successful or not - to cope with them. Due to asymmetry and close contact within the private sphere of the home, relationships between employers, care receivers, and migrant care workers tend to be problematic. Kordasiewicz (2015: 54), for example, calls the relationships of employers and their migrant care workers a "sort of a puzzle to be solved in everyday interaction." Solving this social puzzle may turn out to be very difficult. Therefore, we decided to get back to the data for a secondary analysis to reconstruct these "puzzle-solving strategies" which - as we want to show - are basically linked to the reconstruction of familiarity in the home space.

The process of the secondary analysis used a theoretical coding approach (Strauss \& Corbin 1990). It included two iterative cycles of coding (open and axial), including ongoing comparison between the different cases under study and memo writing. Through open coding we identified central analytical categories of live-in care arrangements such as "aging at a familiar place," "disrupted familiarity," and "doing familiarity" developed as central themes from the interview data. Through axial coding these categories were differentiated and related to each other, resulting in subcodes such as "compromised privacy," "sense of alienation," "transformation of rituals," "contested autonomy," or "familiarize the unfamiliar" (see empirical section).

The interview sample consists of five women and six men aged between 37 and 63. At the time of the interviews, apart from one person who had already retired, all interview partners were employed or self-employed; seven were working full-time and three part-time (between $60 \%$ and $95 \%$ full-time equivalent). Six were graduates, three had a training qualification, and two did not give any information on their educational level. The persons they cared for were between 62 and 99 years old. In nine cases, 
International Journal of Ageing and Later Life

the person in need of care was the mother, in one case mother and sister, and in one case the wife of the interviewee. In the last two cases, the interviewee lived in the same household as the person in need of care and in one case the brother of the interviewed person lived together with the mother who needed care. In seven cases, care needs resulted from dementia, partly combined with other diseases such as Sarcoidosis, Morbus Parkinson, and femoral neck fracture. Other persons suffered from apoplectic stroke, from carcinosis, or complaint osteoarthrosis of old age. All the interviewed family caregivers not only provided, but also organized and supervised care for their relatives.

Regarding the type of live-in care arrangement, the data covered a wide range, including contracts on a weekly (2), monthly (8), and one on a yearly basis. Except for the last one, they all employed several - mostly two or three - migrant care workers who took turns. Out of eleven settings, eight were mediated by agencies, whereof only one agency was regularly registered in Switzerland and hence fulfilled the criteria for international job mediation under Swiss law. In two settings, the contact resulted from informal networks of the migrant care worker or the family caregiver. One household took over the migrant care worker after their neighbors' death. All care workers were female. They were between 24 and 63 years old and came from Poland, Slovakia, Kosovo, or East Germany, the former territory of the German Democratic Republic (GDR).

Compared to its neighboring countries, live-in care arrangements still are rather new in Switzerland. This is basically due to limited cashfor-care transfers and the restrictive immigration law of Switzerland. Switzerland is a partner in the EU free-movement-of-persons agreement since 2011 and only since then migrants from the new EU countries in Central and Eastern Europe have access to the Swiss labor market. The family caregivers interviewed in 2012, thus, stepped onto unfamiliar terrain when employing a migrant home care worker; they were pioneers, and there were few role models and few people - if any - to turn to for advice. In the meantime, the phenomenon has attracted more attention, and live-in care has gained popularity. However, transnational live-in care arrangements are still far from being a common practice in Switzerland. 
Fragile familiarity

\section{Familiarity in the Context of Care}

Etymologically, the term "familiarity" stems from the Latin "familiaritas/ familiaritatem" which signifies intimacy, friendship, and close acquaintance. Working on memory and familiarity among older people with dementia, Son et al. (2002) define familiarity as "thorough knowledge of a subject derived from a close relationship and acquaintance from past experience" (p. 264). They furthermore refer to familiarity as a feeling which occurs as "the product of repeated and frequent exposure to something (e.g. people, objects, scenes, or sounds)" (p. 264). We would argue that this conceptual framing of familiarity as a "feeling" accentuates the potential fluid character of it. It characterizes familiarity as something rather dynamic and potentially fragile which needs to be stabilized by a repetitive time frame pointing to the relevance of frequency and/or continuity. Hence, the feeling of familiarity may be contested when the specific character of the environment (e.g. people, objects, scenes, or sounds) changes. When change occurs, time may play an important role as time may offer (new) opportunities for repeated and frequent contacts within the new environment to (re-)establish a (new) feeling of familiarity. Hence, we understand familiarity, rather than as a given status or fact, as a result of (inter-)action and (repeated) social construction.

We think of familiarity as a social process which - referring to the concept of "doing difference" (West \& Fenstermaker 1995) - could be described as "doing familiarity" (see, e.g. Bowlby et al. 1997; Chambers et al. 2009). The need for "doing familiarity" arises when established routines or settings are challenged. We argue that familiarity is an achievement for which people need to work. They invest to create, to restore or to maintain familiarity. Hence, "doing familiarity" may also be seen as the social process of adaptation to social and environmental changes in the context of ageing and developing care needs.

Familiarity becomes fragile for people with chronic illnesses, as care needs progress - even more for those with degenerative conditions such as dementia or Parkinson's disease. Unfamiliarity creeps in, affects the body and the self, and thereby the most intimate spheres of life. Conditions may change unexpectedly and at any time, one cannot be sure if what one is capable of doing and understanding today is what 
International Journal of Ageing and Later Life

one is able to do and understand tomorrow. And as bodies, capabilities, and personalities change, so do the relations with their human and nonhuman surroundings. Hence, also for family members and relatives of persons with chronic degenerative conditions, coping with (un-)familiarity and adapting to the new circumstances may become central. Consequently, adaptation of established familial role models, developed, enacted, and consolidated over years, may be required due to new responsibilities and dependencies that may be completely unfamiliar for those involved.

Precisely because dealing with unfamiliarity and change in the context of chronic degenerative disease is a major challenge, familiarity with regard to care is crucial. However, familiarity has not yet been broadly discussed in the literature on entry to care (Ryan \& McKenna 2013). Some studies acknowledge the importance of the concept of familiarity, for example, in the context of nursing home placement of older relatives (Davies \& Nolan 2003, 2004; Nolan \& Dellasega 2000; Ryan \& McKenna 2013), but few elaborate it in detail. Ryan and McKenna's (2013) research is exceptional in this respect. It describes familiarity as "the key factor" of family caregivers' experiences when their older relatives have to move to a nursing home. In their study, Ryan and McKenna's focus lies on the family caregivers' familiarity with the nursing home's history, its staff, and fellow residents. They illustrate how the familiarity of the nursing home is based in the rural social life where professional as well as family caregivers and the older people in need of care had been part of the same community over years. Hence, familiarity results from spending life in a socially well-knot community of which the nursing home is part, and the impact of change associated with nursing home entrance accordingly seems to be less threatening to feelings of familiarity. Davies and Nolan (2004) describe a somehow more (socio-) dynamic and emotionally challenging process of "restoring" a feeling of familiarity when moving to a nursing home by describing three phases of transition: making the best of it, making the move, and making it better. This literature discusses threats to or potential loss of familiarity in the context of making the move from home to a nursing home. Hence, familiarity is threatened by leaving home, and, implicitly, one could say, staying at home is supposed to be kind of a warrant for keeping up familiarity. In this paper, however, we intend to illustrate how home is 
becoming unfamiliar through changes in the context of age-related care needs that may challenge specific meanings of the home space and the experiences of familiarity within it.

\section{Home and Privacy - Pivotal Markers of Familiarity}

"[H]ome in its broadest sense is a physical, social, psychological (...), as well as political, environment where an individual's life history with all its relationships contextualised in time and space becomes a part of unpacking meaning and exploring continuity and change" (Peace 2015: 447). This definition stresses that the meaning of home is highly symbolic and that it needs to be understood in the context of the life-trajectories of those emotionally and/or physically "attached" to this particular place. In present-day Western societies, home is generally associated with positive feelings, such as rootedness, intimacy, well-being, comfort, security, warmth, and so on. From feminist research, though, we have learnt not to romanticize home, as it can as well be a site of dominance, violence, conflict, isolation, and entrapment (Peace 2015).

The meaning of home is closely linked to a person's dwelling, but extends the house or apartment and often includes issues of place - from neighborhood to country; there are "many layers of attachment" (Peace 2015: 448). Belonging is crucial here; home is strongly associated with a sense of belonging. The work of Milligan (2005) on home care is an important source for us: first, she looks at the meaning of home from an informal caregiver's perspective and from an emotional geography approach. She deploys what she calls an emotiospatial hermeneutic; that is an approach to understand social realities through the emotional component of spaces. Based on this approach, Milligan (2005) identifies three key elements of "home": (1) the social: relationships between people and interactions; (2) the emotional: feeling of safety, identity, and meaning; and (3) the physical: "incorporates objects and defines boundaries and spaces (and further endows the individual with the power to exclude)." Feelings of familiarity, as introduced above, are closely linked to this conception of home as a space where repeated exposure to people, objects, scenes, or sounds is involved and (shared) biographical experiences lead to an intimate knowledge of this space and, thus, emotions of "feeling familiar." 
International Journal of Ageing and Later Life

The physical and the social undoubtedly are key shapers of home. Home is a place constituted through an assemblage of objects and humans often placed purposefully, and sometimes arbitrary. Emotionally imbued relations create the gravitational power that brings these heterogeneous elements together, and sometimes drives them apart (again). Therefore, according to an emotiospatial approach, the emotional is superordinate because emotions "alter the way the world is for us" and because "place must be felt to make sense" (Milligan 2005: 2105). In other words, emotions are not only key qualities of relations, material objects, and arrangements, but are a way through which to perceive, interpret, and actually make our environment. Home is commonly perceived as a place, but it is foremost a feeling. Familiarity, a feeling defined as knowing and belonging to socio-material environments (see Ryan \& McKenna 2013), is just one, though with respect to home, pivotal example here. Hence, what we call "doing familiarity" may be interpreted as specific social (inter-)actions to create the feeling of familiarity by (re-)making home and redefining the familiar.

However, the "meanings of home in relation to ageing in place are not unambiguous" (Rapoport 2005: 343; cit. in Peace 2015: 447). The notion of "confinement" to home due to, for example, mobility impairments is kind of a "counterpart" which may help to illustrate the kind of ambivalent dimensions of home. So home may be the place where an elderly person is confined to her or his home, which may refer to (1) an unwanted restraint, a limitation or (2) positively viewed - to a place providing security and protection from unwanted intrusion. Although the second dimension is about "[a] feeling of safety within the confines of one's own house" (Bowlby 2012: 2108), the first one refers to a negative emotion, when leaving home may become difficult as a consequence of raising health and care needs, when the public space is not (easily) accessible anymore, when staying at home is no freedom of choice but a limitation due to restricted mobility.

Most research on the notion of home in care settings focuses on the transition from the private household to a care institution. However, with ageing in place, the private household itself undergoes fundamental transformations: Who is entering the household, when and for how long? What happens at home and what is located there? What does the home look like and what kinds of activities are taking place there? Thus, what used to 
be familiar about home may be challenged due to care provision at home as well as by changing physical and cognitive conditions. Angus et al. (2005: 161) show that although there is a strong preference for home care from care recipients and their family caregivers, the practices and experiences within their homes are "disrupted and reconfigured by the insertion of logics emanating from the healthcare field," and that the "domestic and health care fields were superimposed within the space of home," hence logics of home clash with logics of (professional) healthcare. As we will show, the setting we are focusing on in this paper - that is, migrant live-in care arrangements - mixes this up in a somewhat different way: By introducing paid care provision into the home, the live-in arrangement refers to this "superimposition of the care field on the domestic," that is, the fact that another logic - namely, the one of paid-for care provision and its market-related dynamics - may become dominant. However, the specific nature of the live-in arrangements we focus on also tends to (re-)establish relationships and practices that clearly refer to the domestic and hence familial logic (see, e.g. Baldassar et al. 2017 on kinning processes between migrant care workers, the care receivers, and their extended family).

\section{Aging in an Ideal and Familiar Place}

The interviews illustrate that the main reason for engaging a live-in care worker was a clinging to the idea of home as the ideal place to age and to be cared for, despite increasing need for support. This conviction is related to general social norms and current policies that articulate the home as the ideal place of elder care. Our interviews show that on top of that, the expressed conviction is often rooted in a promise.

This is, for example, what Sarah ${ }^{2}$ refers to when talking about her mother with acute and high care needs due to a complicated fracture after a fall:

I just couldn't imagine bringing her to a nursing home. In those days, earlier, we often discussed the issue and she used to say: "It would be nice if one could die at home." And I used to reply to her that I respected this wish and that I would do whatever it takes to make it possible. (Sarah)

$\overline{2}$ All informants' names are pseudonyms. 
International Journal of Ageing and Later Life

Also, Barbara who organized a live-in care arrangement for her mother suffering from dementia clearly refers to a promise given to her mother earlier in live:

[...] it was clear she can stay there, yes we promised her that too, she can stay there, she can be on the farm. Since she has lived there for 50 years. (Barbara)

Anna, who organized a migrant care worker because her mother suffered from Parkinson and dementia, while her father getting older himself, could not cover all the care needed, explained that she felt in charge of keeping a promise their parents gave each other:

My father and mother had promised themselves that they would make sure that they could stay at home as long as possible, even if someone became ill. (Anna)

As these three, all interviewees, were bothered with respect to the wish of their mother or father, they felt a clear moral obligation to fulfill this wish and to keep earlier promises. These quotes can be read as manifestations of intergenerational reciprocity duties (see, e.g. Hollstein 2005) and moral beliefs which influence the care arrangement (see, e.g. Kordasiewicz, Radziwinowiczowna \& Kloc-Nowak 2018). Looking at family care, informal care, and home care, we have to point to life course-specific needs of care, that is, the "importance of the timescale of the human life course and of intergenerational relationships of care" (Bowlby 2012: 2105). Resulting in a generational interdependency, that is, adults care for (their) children and are "repaid" in their old age by care from their (own) children or by care from other able-bodied adults (ibid.). However, this intergenerational reciprocity debt did not always manifest in such an explicit mode as it does in the presented quotes. Sometimes it was more latent and as a subtext built the basis for feeling responsible of facilitating ageing at home. Referring to Bowlby (2012: 2106), one could argue that these emotional and social links expressed by a promise or by a feeling of responsibility represent what she calls "cultures of care" based in a shared family biography and including "pattern[s] of care behavior amongst families (...) learned over time, through relationships between individuals in place and through space."

Our analysis shows that interviewees additionally associated the home with key qualities of care such as (1) autonomy and self-determination as well as (2) compassionate, personal, and individual care. On top of this, 
Fragile familiarity

some interviewees articulated the home as a therapeutic landscape with the potential to maintain or improve well-being of the person cared for.

It is so important that they feel comfortable and are in their familiar surroundings, even if they live in a completely different time, but when they come back and see, that is still what they are used to...the familiarity of one's own home that is something very important. (Peter)

Like in this quote of Peter who had engaged a migrant care worker to take care of his mother suffering from severe dementia (what he refers to when saying she lives in a completely different time), a familiar environment was repeatedly explained to be a crucial quality of care by all the interviewees. First, doctors would see it as key to cope with dementia, a disease that entails increasing degrees of confusion. Second, a familiar environment was seen as stimulating not only because it allows continuing with simple household chores, but also because neighbors and friends stop by and generate interaction. These statements underpin the meaning of home as a focal point of most people's lives, and the relevance of daily practices involved in maintaining home, such as cleaning, cooking, or caring, which may be understood as domestic rituals that serve to develop the emotional and social meanings of home by "restoring symbolic boundaries and meaningful categories" (Cieraad 1999: 11). Our analysis, though, shows that the continuity of place did not imply continuity in familiarity per se because when an unknown person, that is, in our cases a live-in migrant care worker, enters the home, the very nature of this place changes.

\section{Experiences of Disrupted Familiarity}

\section{A Sense of Alienation and Compromised Privacy}

In fact, a variety of things change, both material and social. With a "stranger" in the house, there is a sense of alienation. This is what the quote of Sarah makes clear:

I realized that mum had difficulty with somebody being in the house for 24 hours, and a stranger. She would have preferred me to be there, but this was not feasible. (...) I realized that it is strange, for a woman who had lived on her own, had got everything done on her own. But I guess she understood that there was no alternative. (Sarah) 
International Journal of Ageing and Later Life

The fact that someone unknown is continuously present in the home is clearly stated as being highly irritating for the mother. Here, a person perceived as a stranger virtually becomes a cohabitant; hence, privacy is compromised because someone nonfamiliar is physically present in the private space of the home around-the-clock. As the quote makes clear, the presence of a more familiar person, that is, the daughter, would have been preferred.

As the mother depends on the care the "stranger" will provide, her endowment to exclude this person from home is compromised. This seems to be specifically challenging as the mother used to be an independent person able to organize her life on her own. What pops up here in addition to the dichotomy of the strange, represented by the live-in caregiver, and the familiar, represented by the daughter, is the issue of dependence as a counterpart to the ideal of autonomy. Although one could argue that becoming dependent is a challenge to the mother-daughter relationship, as shifting responsibilities arise, this seems less threatening than the entrance of the stranger into the home.

Similar to the shifting roles of mother and daughter, dimensions of power are at play as well. Although the daughter acknowledges the emotional challenge the live-in arrangement means to her mother, the daughter makes clear that the more familiar option (i.e. herself being there) is not feasible for her. Hence, her mother does not have a choice; she realizes that there is no alternative solution. To be able to stay at home, that is, the supposed most familiar place, implicates the need to cope with a maximum challenge to the very quality of the same, that is, to deal with the alienation of home by the comprehensive presence of a stranger.

Referring to the literature on ambivalence within intergenerational relationships (see, e.g. Lettke \& Lüscher 2002; Lüscher 2005), one could critically question the supposed harmony between family members when comprehensive care needs arise. This is what the following quote of Samuel who engaged a live-in care worker for his 88-year-old mother points to:

It's not all sheer joy - you wouldn't have had vain joy with father either. (Samuel)

Samuel compares the challenging quality of the live-in care arrangement with the potential experience of further living together with her 
husband (who had died some years before). Of course, to be cared for by a family member neither guarantees the absence of conflicts nor the presence of harmony. However, care and support would be organized within the established modes and biographically shaped forms of potential conflict or harmony, that is, within the relationship both familiar to the person in need of care as well as to the caregiver.

\section{Transformation of Habits and Rituals}

As a consequence of the continuing presence within the home space, the live-in care worker constitutes a significant other. The live-in care worker represents an active subject which wants to get things done, requests responses, and has a professional mission to accomplish. Samuel repeatedly reflected on these challenges in relation to daily routines. His mother and the live-in care worker have to share part of their life with someone who - at least at the beginning - is a stranger, someone from another country who, if at all, only basically speaks their language. They have to develop and implement shared daily routines without really having any joint experiences they could refer to. Hence, they need to negotiate to try to make things clear and to organize tasks and distribute household chores. This may turn out to be rather challenging:

[...] well, now this woman [the live-in care worker] enters my mother's life and begins to take up space and to work according to her own ideas. That's not easy. [...] And my mother couldn't make her needs clear. I asked once in a while when there was a friction How did you express this to her [the live-in care worker]? And, I said, I understand, because I am your son and I know how she thinks. (Samuel)

The challenge here is not just about a lack of language skills. Rather, the lack of familiarity becomes apparent. The son makes clear that he understands what his mother wanted to express only because they share a joint history. If the mother wants to communicate her concerns, she must do this in a way that is understandable to the live-in care worker. This tangles language skills, but goes far beyond it. Although the content of the communication may refer to intimate daily routines in the home space, one cannot refer to familiar frames of references, as the two persons involved do not (yet) share any joint experiences necessary 
International Journal of Ageing and Later Life

for this. Although they do live together, they are strangers to each other. What is needed here is a language that bridges between the individual past of the persons involved and the shared present. Furthermore, there is a need for a specific style of communication that links the intimate quality of the topics (intimate because it is about rituals, habits, individual preferences, and so on) to the fact that the relationship is not (yet) an intimate or familiar one. Hence, one could argue, the professional logic of the arrangement clashes with the domestic one.

\section{Compromised Autonomy and Contested Self-Determination}

The entrance of a live-in care worker also transforms habits and challenges familiar rituals in a very profound way. As already stated, daily practices such as cleaning or cooking are basic for creating familiarity in the domestic space (Cieraad 1999). Respectively, food was often mentioned in the narratives, referring to different traditions on how to prepare meals, to what counts as healthy food, or what kind of food one is used to, and so on. Samuel reports about friction points in this respect:

For example, she [the live-in caregiver] thought that, because my mother was having coffee and bread for breakfast, as many elderly people do, that her diet was unbalanced. So, she prepared muesli for breakfast. My mother said: "In my entire life I never had muesli for breakfast." And the carer said: "This is healthy." My mother said: "That's true, but I don't have muesli for breakfast." [The carer replied:] "Nevertheless, you eat breakfast, it's healthy." These are the kinds of things the two didn't really get along. (Samuel)

Food debates like this one illustrate the multifold dynamics of the superimposition of the foreign, that is, unfamiliar logics into the familiar daily routines of the home space. In this quote, the live-in caregiver in fact takes her job rather serious and wants to optimize the diet of the person in need of care - also against her will. Samuel further reflected on the fact that his mother felt oppressed and also explicitly expressed that she "did not want to obey." She obviously thought she'd left these things behind at her age. What is central in the quote in relation to familiarity is the term "in my entire life" which clearly refers to rituals and habits that are challenged by the introduction of a new diet for breakfast considered to 
be healthier by the migrant care worker. Again, power dimensions ${ }^{3}$ turn out to be crucial as well as a tension between the professional mission of the live-in care worker and the habits and preferences of the person in need for care. ${ }^{4}$

\section{"Doing Familiarity" - Ways to Cope with New Situations}

The interviews illustrate a range of conflicting power dynamics represented through the attempts of mutual domestication of the person in need of care and of the live-in caregiver, which may be summarized into the question: Who adapts how and to which changes? The interviews reveal a variety of adaptions to the new situation. Generally, we could find two ways of dealing with change and unfamiliarity in the interviews: (1) adaptation to the new situation, and (2) introduction of another change to circumvent unfamiliarity.

One form of adaption is to transform the unfamiliar into a familiar thing. For example, both the person in need of care and the live-in care worker might accept changing their habits. This includes reinterpreting and adapting over time. And often, it does not go without conflicts. Family caregivers turned out to put in a lot of time and effort to mediate between the cared-for and the live-in care workers. Making the unfamiliar familiar by reinterpreting and adapting is a strategy that also applies to the live-in care worker as a person. The interviews contain various instances that indicate that the subject position of the live-in care worker is shifted from a strange outsider and a paid-for care worker to a member of the family.

The caregiver can become part of the family. She was part of us somehow. We spent a lot of time together. I mean, I was there every day. And although it was only for two weeks, a bonding developed. (Sarah)

\footnotetext{
${ }^{3}$ It is important to note that power asymmetries exist between the live-in care giver and the person in need of care or his/her family in both directions. As a consequence of our focus on the notion of familiarity in live-in care and how it is negotiated by the interviewed family caregivers, however, the vulnerable dimension of the live-in care worker is less addressed in our data. ${ }^{4}$ Although live-in caregivers usually come from places that are deemed culturally different from Switzerland, reference to cultural differences was largely confined to food and cooking habits. Consistent with van Holten \& Soom Ammann (2016), cultural difference was largely used to explain irritating behavior and encounters in our data set.
} 
International Journal of Ageing and Later Life

Thus, adaptation is here done via attempting to redefine the "stranger" as "being part of the family." When employed caregivers become quasi-family members, their position in the social network changes. This strategy, also referred to as "kinning process" (Baldassar et al. 2017), refers to kinship as something not constituted by pure biological ties but rather as something "fundamentally relational and performative" which is "negotiated on a daily basis through diverse activities, with caregiving being the most significant" (Baldassar et al. 2017: 526).

Moving away from the subject position of a paid worker, however, blurs the boundaries between leisure and work even more (see Truong 2011). Some caregivers, for example, were invited to family events, and, although they started to take care of the guests or to clean the kitchen, their participation was considered as spare time. One migrant caregiver even accompanied the person in need of care and her family caregiver to a holiday, but it was framed as the caregiver's holiday, too. However, as compassionate care is viewed as crucial, it also renders the live-in caregiver as non- or at least less replaceable. This increases the household's dependency on them. So, shifting the live-in caregiver's subject position toward a family member implies complex asymmetries and can simultaneously work to the advantage or disadvantage of the live-in caregiver.

Time and continuity are two central aspects of adaptation and doing familiarity. Adaptation is described in the interviews as a mutual approach, getting to know each other, and getting "closer." This requires an intensive learning process for all involved, at the end of which familiarization potentially can take place. This is illustrated by the following quotation, in which Samuel reports on everyday situations that have meanwhile become harmonious:

\footnotetext{
And now so over the two and a half years they have got used to each other and know how the other one thinks, and that has also relaxed a little bit.[...] When I sometimes visit them and I see them sitting in front of the big window, looking down into the valley and drinking coffee, so harmoniously together, then I have the feeling that it can't be that bad. Or when I see them working together in the garden and planting creatively in a way and, afterwards I think, it's still in a way a hand-in-hand walk. (Samuel)
}

However, the described familiarity remains a fragile achievement, which can be contested at any stage. Continuity and regularity are important prerequisites. Often, family caregivers tried to extend the working contract 
to achieve more continuity, which was not always possible due to restrictions of the intermediary agency, restrictive migration policies or individual preferences of the migrant care worker. Those arrangements in which turn-taking of the migrant care workers was very frequent or where they only stayed for a short time, that is, 1 or 2 weeks, and did not come back again were considered as unsatisfactory by the interviewees. This may be understood as a direct consequence of the failure of restoring familiarity over time. Nevertheless, when the same two or three migrant women took turns, a certain familiarity could be achieved. What was striking here was that usually one of the migrant women stood out as particularly reliable and delivering extraordinary care services in comparison to the other care workers involved. This may be seen as an attempt to construct one main caregiver among the changing caregivers who stands out due to specific individual characteristics and hence fits the care arrangements at its best. Hence, this represents a further realization of the "doing familiarity" strategy.

Another form of adaption is to accept the new as something unfamiliar that might well remain strange. This includes a transformation of the notion of home; it now includes unfamiliar elements. The unfamiliar elements might not be bothering or they might be the bitter pill one is ready to swallow for the higher aim of staying at home. The last sentence of the first quote indicates this trade-off: "But I guess she realized that there was no alternative."

\section{Conclusions}

Based on the analyses we intended to illustrate that familiarity is a result of (inter-)action and social construction, rather than a given status or fact. Hence, we understand familiarity as relational; it describes a dynamic relation between persons, their resources, and their environment. Furthermore, familiarity is associated with recognition, repetition, continuity, stability, and safety, with time and space being further relevant factors of familiarity, pointing to the experiences in the past and the meanings of specific places such as, for example, the home. Hence, we understand familiarity as a condition that is threatened by change.

Change, that is, encountering new environments and situations, is challenging or even shattering familiarity by evoking feelings of unfamiliarity. Experiencing unfamiliarity may result in not only alienation 
International Journal of Ageing and Later Life

and confusion but also curiosity to explore and understand the novelty. With time and through reinterpretation and adaptation, the new situation might be integrated into a relation of familiarity to a new set of entities, and familiarity might be restored. Or change leads to a lingering feeling of strangeness. We call this reinterpretation and adaptation to change the "work" that is needed to achieve familiarity. This further implies that familiarity is a precarious condition, always at risk of being questioned or brought down.

Hiring a live-in caregiver allowed care recipients to stay at home and family caregivers keeping their promise to facilitate ageing at home. Hiring a live-in caregiver did not, though, allow continuing some of the core qualities that were associated with home care. As we have shown, autonomy and privacy are both compromised, at least temporarily. This is important because often they were the very reason to maintain home care and hire a live-in caregiver.

Autonomy and privacy are both closely linked to control. Milligan (2005: 2107) notes: "The transition of care to a care-home setting marks a clear shift in the balance of power in the caregiving relationship from informal to formal caregivers. Informal carers and care recipients lose the ability to exclude" and define the terms of how care is delivered. While with a live-in care arrangement the family caregiver and care recipient keep in control to some extent, we have also shown that this control, due to the complex asymmetries at work, can be rather limited and need to be worked on.

Our empirical data suggest that there are different ways of dealing with threats to familiarity. All of them imply work: adapting to or searching for new arrangements entail efforts, emotional and physical. The interviews clearly showed that taking in a live-in caregiver entails change that is not easily shrugged away for all involved parties. For some, the price is too high. If the effort to adapt and re-establish familiarity at home was considered too intensive or not worthwhile, the agreement with the live-in caregiver was resigned and the person in need of care had to enter a nursing home.

Research has highlighted that care migration entails a problematic transnational transfer of care work. Caregivers who come to work in Northwestern European countries are missing in their home countries. Our research offers a more nuanced picture on the nitty-gritty everyday 
life in live-in care arrangements, and it reveals the complexity of adapting to it. Foremost, it challenges the idea that remaining at home is about continuity. It probably is as much about change as moving to a nursing home.

\section{Corresponding Author}

Karin van Holten, Careum School of Health, Kalaidos University of Applied Sciences, Pestalozzistrasse 5, 8032 Zurich, Email: karin.vanholten@ careum-hochschule.ch.

\section{References}

Allan, G. \& Crow, G. (2001). Families, Households, and Society. Sociology for a Changing World. Basingstoke, NY: Palgrave.

Anderson, A. (2012). Europe's care regimes and the role of migrant care workers within them. Population Ageing 5(2): 135-146. doi:10.1007/ s12062-012-9063-y

Angus, J., Kontos, P., Dyck, I., McKeever, P. \& Poland, B. (2005). The personal significance of home: Habitus and the experience of receiving long-term home care. Sociology of Health \& Illness 27(2): 161-187. doi:10.1111/j.1467-9566.2005.00438.x

Baldassar, L., Ferrero, L. \& Portis, L. (2017). More like a daughter than an employee: The kinning process between migrant care workers, elderly care receivers and their extended families. Identities, Global Studies in Culture and Power 24(5): 524-541. doi:10.1080/1070289X.2017.1345544

Bettio, F. \& Verashchagina, A. (2010). Long-Term Care for the Elderly. Provisions and Providers in 33 European Countries. Synthesis Report for the Use of the European Commission [Internet]. Directorate- General Justice, Unit D1 "Gender Equality." Available on https://doi.org/ 10.2838/87307 (Accessed: September 1, 2019).

Bischofberger, I. (2011). Angehörige als wandelnde Patientenakte: Ausgewählte Ergebnisse aus einem Projekt zur Klärung der Rolle der Angehörigen. [Family caregivers as walking patient-records: Selected results from a project to clarify the role of family caregivers]. Care Management 4(5): 27-29.

Bowlby, S. (2012). Recognising the time - Space dimensions of care: Caringscapes and carescapes. Environment and Planning A 44(9): 2101-2118. 
International Journal of Ageing and Later Life

Bowlby, S., Gregory, S. \& McKie, L. (1997). Doing home: Patriarchy, caring, and space. Women's Studies International Forum 20(3): 343-350.

Chambers, P., Allan, G. \& Phillipson, C. (2009). Family Practices in Later Life. Ageing and the Lifecourse Series: 2009: 1. Bristol: Policy.

Chiatti, C., Di Rosa, M., Melchiorre, M. G., Manzoli, L., Rimland, J. \& Lamura, G. (2013) Migrant care workers as protective factor against caregiver burden: Results from a longitudinal analysis of the EUROFAMCARE study in Italy. Aging \& Mental Health 17(5): 609-614.

Cieraad, I. (1999). At Home: An Anthropology of Domestic Space. Syracuse: Syracuse University Press.

Colombo, F., Llena-Nozal, A., Mercier, J. \& Tjadens, F. (2011). Help Wanted?: Providing and Paying for Long-Term Care. Paris: OECD.

Davies, S. \& Nolan, M. (2003). "Making the best of things": Relatives' experiences of decisions about care-home entry. Ageing and Society 23(04): 429-450. doi:10.1017/S0144686X03001259

Davies, S. \& Nolan, M. (2004). "Making the move": Relatives' experiences of the transition to a care home. Health and Social Care in the Community 12(6): 517-526.

De Pietro, C., Camenzind, P., Sturny, I., Crivelli, L., Edwards-Garavoglia, S., Spranger, A. \& Quentin, W. (2015). Switzerland: Health system review. Health Systems in Transition 17(4): 1-288.

Di Santo, P. \& Ceruzzi, F. (2010). INTERLINKS: Migrant Care Workers in Italy: A Case Study. Rome/Vienna: Studio Come.

Doh, M., Schmidt, L. I., Herbolsheimer, F., Jokisch, M. R., Schoch, J., Dutt, A. J., Wahl, H.-W. (2016). Neue Technologien im Alter. Ergebnisbericht zum Forschungsprojekt "FUTA": Förderliche und hinderliche Faktoren im Umgang mit neuen Informations- und Kommunikations-Technologien im Alter.[New Technologies in Old Age. Report on the Results of the Research Project "FUTA": Promoting and Hindering Factors in Dealing with New Information and Communication Technologies in Old Age.] Available on Abteilung für Psychologische Alternsforschung, Psychologisches Institut der Universität Heidelberg website: http:/ / www.psychologie. uni-heidelberg.de/mediendaten/ae/apa/futa-ergebnisbericht_2015. pdf (Accessed: May 19, 2019).

Dyck, I., Kontos, P., Angus, J. \& McKeever, P. (2005). The home as a site for long-term care: Meanings and management of bodies and spaces. Health \& Place 11(2): 173-185. doi:10.1016/j.healthplace.2004.06.001 
England, K.\&Dyck,I.(2011). Managing thebody work of homecare. Sociology of Health and Illness 3(2): 206-219. doi: 10.1111/j.1467-9566.2010.01331.x

Federal Statistical Office. (2015). Statistik der Hilfe und Pflege zu Hause: Ergebnisse 2014 : Zahlen und Trends. [Statistics help and care at home: Results 2014: Figures and trends]. Neuchâtel: Federal Statistical Office.

Federal Statistical Office. (2017). Spitex-Statistik 2011-2016. [Statistic of Out-of-Hospital Care]. Available on https://www.bfs.admin.ch/bfs/ de/home/statistiken/gesundheit/gesundheitswesen/hilfe-pflegehause.assetdetail.3782039.html (Accessed: May 28, 2018).

Frey, M., Meier, H., Suri, M. \& Walthert, L. (2016). 24-StundenBetagtenbetreuung in Privathaushalten. Regulierungsfolgen-abschätzung $z u$ den Auswirkungen der Lösungswege gemäss Bericht zum Postulat Schmid-Federer 12.3266 «Pendelmigration zur Alterspflege», B, S, S Volkswirtschaftliche Beratung, Studie im Auftrag des Staatssekretariats für Wirtschaft, Schlussbericht vom 29. Februar 2016. [24-Hours Care for the Elderly in Private Households. Regulatory Impact Assessment According to the Report on the Schmid-Federer Postulate 12.3266 "Circular Migration in the Context of Elderly Care", B, S, S Economic consulting, study commissioned by the State Secretariat for Economic Affairs, final report of 29 February 2016.]

Füglister-Dousse, S., Dutoit, L. \& Pellegrini, S. (2015). Soins de longue durée aux personnes âgées en Suisse: Evolutions 2006-2013 [Long-Term Care for the Elderly in Switzerland: Developments 2006-2013]. (Obsan Rapport No. 67). Neuenburg. Available on Schweizerisches Gesundheitsobservatorium website: https://www.obsan.admin.ch/sites/default/files/publications/2015/obsan_67_rapport.pdf (Accessed: May 28, 2018)

Genet, N., Boerma, W., Kroneman, M., Hutchinson, A. \& Saltman, R. B. (2012). Home Care across Europe. Current Structure and Future Challenges. European Observatory on Health Systems and Policies. Observatory Studies Series 27. Copenhagen: World Health Organisation.

Haak, M., Fänge, A., Iwarsson, S. \& Ivanoff, S. D. (2007). Home as a signification of independence and autonomy: Experiences among very old Swedish people. Scandinavian Journal of Occupational Therapy 14(1): 16-24. doi:10.1080/11038120601024929

Hollstein, B. (2005): Reziprozität in familialen Generationenbeziehungen. [Reciprocity in generational family relationships]. In F. Adloff \& S. Mau (eds.), Vom Geben und Nehmen. Zur Soziologie der Reziprozität 
International Journal of Ageing and Later Life

[From Giving and Taking. On the Sociology of Reciprocity.] (pp. 187-210). Frankfurt a. Main: Campus Verlag.

Huang, S., Yeoh, B. \& Toyota, M. (2012). Caring for the elderly: The embodied labour of migrant care workers in Singapore. Global Networks 12(2): 195-215. https:// doi.org/10.1111/j.1471-0374.2012.00347.x

Jähnke, A. \& van Holten, K. (2013). Care-migration: Verschiedene Akteure im Privathaushalt: Lokale Zusammenarbeit und globale Vernetzung [Care migration: Different actors in the private household: Local cooperation and global networking]. NOVAcura 44(9): 32-35.

Jähnke, A. \& van Holten, K. (2015). Vielfalt der Akteure in der häuslichen Versorgung. [Diversity of actors in domestic care]. FMC Impulse, (2). Available on https://fmc.ch/de/fmc-publikation/fmcimpulse/ angehoerige-freiwillige-und-care-migrantinnen-in-derpflege (Accessed: May 18, 2019).

Kordasiewicz, A. (2015): Class guilt? Employers and their relationships with domestic workers in Poland. In A. Triandafyllidou \& S. Marchetti (eds.), Employers, Agencies and Immigration. Paying for Care. Research in Migration and Ethnic Relations Series (pp. 53-72). Surrey \& Burlington: Ashgate.

Kordasiewicz, A., Radziwinowiczowna, A. \& Kloc-Nowak, W. (2018). Ethnomoralities of care in transnational families: Care intentions as a missing link between norms and arrangements. Journal of Family Studies 24(1): 76-93.

Lamura G. (2013). Pflegekräfte mit Migrationshintergrund in der Langzeitpflege. In: G. Bäcker G. \& R. Heinze (eds.), Soziale Gerontologie in gesellschaftlicher Verantwortung [Social Gerontology in Social Responsibility]. (pp. 307-314). Wiesbaden: Springer VS.

Lettke, F. \& Lüscher, K. (2002). Generationenambivalenz - Ein Beitrag zum Verständnis von Familie heute. [Generation ambivalence - A contribution to the understanding of the family]. Soziale Welt. Zeitschrift für sozialwissenschaftliche Forschung 53(4): 437-466.

Levine, C., Halper, D., Peist, A. \& Gould, D. A. (2010). Bridging troubled waters: Family caregivers, transitions, and long-term care. Health Affairs 29(1): 116-124. doi:10.1377/hlthaff.2009.0520

Levine, C., Halper, D., Rutberg, J. L. \& Gould, D. A. (2013). Engaging Family Caregivers as Partners in Transitions: TC-QulC: A Quality Improvement Collaborative. New York: United Hospital Fund. Available on www. uhfnyc.org (Accessed: May 18, 2019). 
Lüscher, K. (2005). Ambivalenz. Eine Annäherung an das Problem der Generationen [An approach to the problem of generations]. In U. Jureit \& M. Wildt (eds.), Generationen. Zur Relevanz eines wissenschaftlichen Grundbegriffs [Generations. Relevance of a Basic Scientific Term] (pp. 53-78). Hamburg: Hamburger Edition.

Lutz, H. (2011). The New Maids: Transnational Women and the Care Economy. London \& New York: Zed Books; Distributed in the USA exclusively by Palgrave Macmillan.

Mayring, P. (2007). Qualitative Inhaltsanalyse. Grundlagen und Techniken [Qualitative Content Analysis. Basic Principles and Techniques]. Weinheim: Beltz.

Medici, G. (2011). Hauswirtschaft und Betreuung im Privathaushalt: Rechtliche Rahmenbedingungen [Housekeeping and Support in Private Households: Legal Framework Conditions]. Juristisches Dossier [Legal Dossier]. Zürich.

Medici, G. (2016). Verfassungsrechtliche Perspektive auf die Pendelmigration zur Alterspflege in schweizerischen Privathaushalten [Constitutional Perspective on Care Migration for the Elderly in Swiss Private Households]. Pflegerecht (2), 79-91.

Metz-Göckel, S., Morokvasić, M. \& Münst, A. S. (2008). Migration and Mobility in an Enlarged Europe: A Gender Perspective. Opladen, Farmington Hills, MI: Budrich.

Milligan, C. (2000). "Bearing the burden": Towards a restructured geography of caring. Area 32(1): 49-58. doi:10.1111/j.1475-4762.2000.tb00114.x

Milligan, C. (2005). From home to "home": Situating emotions within the caregiving experience. Environment and Planning A: Economy and Space 37(12): 2105-2120.

Milligan, C. \& Wiles, J. (2010). Landscapes of care. Progress in Human Geography 34(6): 736-754. doi:10.1177/0309132510364556

Nare, L. (2012). The ethics of transnational market familism: Inequalities and hierarchies in the Italian elderly care. Ethics and Social Welfare 7(2): 184-197.

Nolan, M. \& Dellasega, C. (2000). «I really feel I've let him down»: Supporting family carers during long-term care placement for elders. Journal of Advanced Nursing 31(4): 759-767. doi:10.1046/j.1365-2648.2000.01346.x

OECD. (2011). Reviews of Health Systems: Switzerland 2011. Paris. Available on OECD website: http://www.oecd.org/switzerland/ 
International Journal of Ageing and Later Life

oecdreviewsofhealthsystems-switzerland.htm (Accessed: May 18, 2018)

Otto, U., Abele, L., Klein, P. \& Steffen, G. (2014). Älter werden in München: Die 55- bis 75-Jährigen: Ergebnisse einer repräsentativen Erhebung in 5 Stadtteiltypen.[Getting Older in Munich: The 55- to 75-Year-Olds: Results of a Representative Survey in 5 District Types]. Kurzfassung. Unveröffentlichtes Manuskript. [Short version. Unpublished manuscript] Stuttgart: Weeber+Partner.

Otto, U., Zanoni, S. \& Wepf, H. (2015). Evaluation des Projekts «Älter werden im Quartier» Stadt Frauenfeld [Evaluation of the Project "Getting Older in the Neighbourhood" City of Frauenfeld]. Unveröffentlichter Zwischenbericht. [Unpublished Interim Report].

Peace, S. (2015). Meanings of home and age. In J. Twigg \& W. Martin (eds.), Routledge Handbook of Cultural Gerontology (pp. 447-454). New York \& Oxon: Routledge.

Petry, H., Naef, R., Rüesch, P., Mahrer-Imhof, R. \& Dreizler, J. (2016). Erfahrungen von älteren Menschen und deren Familien mit einer Rundum-die-Uhr-Betreuung durch Care MigrantInnen - Eine Grounded Theory Studie [Older Persons and their Families' experience with live-in foreign home care workers - A grounded theory study]. Pflege 29(6), 301-314. doi:10.1024/1012-5302/a000515

Rapoport, A. (2005). On using "home" and "place". In G.D. Rowles \& H. Chaudbury (eds.). Home and identity in late life. (pp. 343-360). New York: Springer Publishing Company.

Rodrigues, R., Schulmann, K., Schmidt, A., Kalavrezou, N. \& Matsaganis, M. (2013). The Indirect Costs of Long-term Care. Research Note 8 for the European Commission Directorate-General for Employment, Social Affairs and Inclusion.

Rostgaard, T., Glendinning, C., Gor, C., Szebehely, M., Theobald, H. \& Timonen, V. (2001). LIVINDHOME Living Independently at Home: Reforms in Home Care in 9 European Countries. Copenhagen: Danish National Centre for Social Research.

Rudin, M. \& Strub, S. (2014). Zeitlicher Umfang und monetäre Bewertung der Pflege und Betreuung durch Angehörige: Datenzusammenstellung, Factsheet [Time Scale and Monetary Evaluation of Care and Support by Relatives: Compilation of Data]. Bern. Available on http://www.spitex.ch/FuerFachleute/Publikationen/Studien/PUpgM/?id=DF4B7107-A266-345 
C-B684D68E7956BF3D\&method $=$ article.detail $\& p=1 \& c=\&$ ref_c $=\& m=$ (Accessed: May 18, 2018).

Ryan, A. \& McKenna, H. (2013). "Familiarity" as a key factor influencing rural family carers' experience of the nursing home placement of an older relative: A qualitative study. BMC Health Services Research 13, 252. doi:10.1186/1472-6963-13-252. Available on https://www.ncbi.nlm. nih.gov/pmc/articles/PMC3704947/ (Accessed: 18 May, 2019).

Schilliger, S. (2014). Pflegen ohne Grenzen? Polnische Pendelmigrantinnen in der 24h-Betreuung. Eine Ethnographie des Privathaushalts als globalisiertem Arbeitsplatz [Care without Borders? Polish Care Migrants in 24-Hour Care. An Ethnography of the Private Household as a Globalized Workplace]. Dissertation. Basel: Universtät Basel.

Schwiter, K., Berndt, C. \& Truong, J. (2015). Neoliberal austerity and the marketisation of elderly care. Social \& Cultural Geography 19(7): 1-21. doi:10.1080/14649365.2015.1059473

Shutes, I. \& Chiatti, C. (2012). Migrant labour and the marketization of care for older people: The employment of migrant care workers by families and service providers. Journal of European Social Policy 22(4): 392-405.

Silverstein, M. \& Giarrusso, R. (2010). Aging and family life: A decade review. Journal of Marriage and the Family 72(5): 1039-1058. doi:10.1111/ j.1741-3737.2010.00749.x

Son, G.-R., Therrien, B. \& Whall, A. (2002). Implicit memory and familiarity among elders with dementia. Journal of Nursing Scholarship 34(3): 263-267.

Steptoe, A., Deaton, A. \& Stone, A. A. (2015). Subjective wellbeing, health, and ageing. The Lancet 385(9968): 640-648. doi:10.1016/S0140-6736(13) 61489-0

Strauss, A. \& Corbin, J. (1990). Basics of Qualitative Research: Grounded Theory Procedures and Techniques. Newbury Park, CA: Sage.

Truong, J. (2011). Arbeit, Arbeitsidentitaet, Arbeitsplatz. Die neuen Wanderarbeiterinnen in der Sorgewirtschaft. [Work, work identity, workplace. The new migrant workers in the care economy]. Zurich: University of Zurich.

Truong, J., Berndt, C. \& Schwiter, K. (2012). Arbeitsmarkt Privathaushalt. Charakteristika der Unternehmen, deren Beschaeftigungsstruktur und Arbeitsbedingungen. Eine Studie im Auftrag der Fachstelle fuer Gleichstellung der Stadt Zuerich [The Private Household as Labour Market. Characteristics of Companies, their Employment Structure and 
International Journal of Ageing and Later Life

Working Conditions. A Study Commissioned by the Office for Equality of the City of Zurich]. Zurich.

Twigg, J. (2001). Bathing: The Body and Community Care. New York \& Florence: Routledge; Taylor \& Francis Group Distributor.

van Holten, K., Jähnke, A. \& Bischofberger, I. (2013). Care-Migration Transnationale Sorgearrangements im Privathaushalt. [Care Migration Transnational Care Arrangements in the Private Household]. Obsan Bericht: Vol. 57. Neuchâtel: Schweizerisches Gesundheitsobservatorium. Available on www.obsan.admin.ch (Accessed: May 18, 2019).

van Holten, K. \& SoomAmmann, E. (2016). Negotiating the potato: The challenge of dealing with multiple diversities in elderly care. In V. Horn \& C. Schweppe (eds.), Routledge Research in Transnationalism. Transnational Aging. Current Insights and Future Challenges (1st ed., pp. 200-216). New York: Routledge.

van Hooren, F. (2012). Varieties of migrant care work: Comparing patterns of migrant labour in social care. Journal of European Social Policy 22(2): 133-147.

Werner, S., Kraft, E., Mohagheghi, R., Meuli, N. \& Egli, F. (2016). Angebot und Inanspruchnahme von intermediären Strukturen für ältere Menschen in der Schweiz: Ergebnisse aus einer Kantonsbefragung und einer Auswertung der Statistik der sozialmedizinischen Institutionen [Provision and Utilization of Intermediary Services for Older People in Switzerland: Results from a Cantonal Survey and an Evaluation of Statistics from Social Medical Institutions]. Obsan Dossier, (52), 1-43. Available on http://www. obsan.admin.ch/sites/default/files/publications/2016/obsan_dossier_52_1.pd (Accessed: May 18, 2019).

West, C. \& Fenstermaker, S. (1995). Doing difference. Gender and Society 9(1): 8-37.

Williams, F. (2012). Converging variations in migrant care work in Europe. Journal of European Social Policy 22(4): 363-376.

Yeates, N. (2011). Going global: The transnationalization of care. Development and Change 42(4): 1109-1130. 